\title{
Social support and cognitive processing among elderly caregivers and non-caregivers of other elderly persons
}

\author{
Wellinton Lucas Silva de Almeida' \\ Ana Carolina Ottaviani2 \\ Bruna Rodrigues dos Santos ${ }^{2}$ \\ Allan Gustavo Brigola ${ }^{2}$ \\ Tábatta Renata Pereira de Brito ${ }^{3}$ \\ Sofia Cristina Lost Pavarini ${ }^{4}$
}

\section{Abstract}

Objective: to analyze measures of social support and cognitive processing among elderly caregivers and non-caregivers. Method: a comparative, cross-sectional and quantitative study was performed. Participants were divided into two groups: 41 elderly caregivers of other elderly persons (G1) and 41 elderly non-caregivers (G2). Sociodemographic, health and care variables, social support, cognition and cognitive processing (verified by long-latency auditory evoked potential acquisition with the Neuron-Spectrun-4 / EPM device) were assessed. Results: in G1, the majority were female ( $\mathrm{n}=33,80.5 \%$ ), married $(n=34,82.9 \%)$, with a mean age of $68.5( \pm 5.8)$ years, a mean $4.5( \pm 3.7)$ years of schooling and had provided care on average for $18.0( \pm 18.4)$ years for $6.5( \pm 5.1)$ hours per day. In $G 2$, the majority were female $(n=31,75.6 \%)$, widowed ( $n=23,56.1 \%)$, had a mean age of $69.8( \pm 7.2)$ years and a mean $3.7( \pm 2)$ years of schooling. There were no statistically significant differences between the groups in social support, cognition and cognitive processing. Conclusion: the task of caring did not have a negative influence on social support and cognitive processing. This research may contribute to the planning of actions among primary health care providers and to future research investigating other factors that permeate this relationship.

1 Universidade Federal de São Carlos, Departamento de Gerontologia, Programa de Graduação em Gerontologia. São Carlos, São Paulo, Brasil.

2 Universidade Federal de São Carlos, Programa de Pós-graduação em Enfermagem. São Carlos, São Paulo, Brasil.

3 Universidade Federal de Alfenas, Faculdade de Nutrição, Programa de Pós-graduação em Ciências. Alfenas, Minas Gerais, Brasil.

4 Universidade Federal de São Carlos, Departamento de Gerontologia, Programa de Pós-graduação em Gerontologia. São Carlos, São Paulo, Brasil.

Funding: Fundação de Amparo à Pesquisa do Estado de São Paulo (FAPESP), process: 2016/21521-7 and 2017/04129-9. Conselho Nacional de Desenvolvimento Científico e Tecnológico (CNPq) process: 424789/2016-7.

Correspondence

Sofia Cristina Lost Pavarini

sofiapavarini@gmail.com
Keywords: Caregivers.

Social Support. Health of the Elderly. Cognition. 


\section{INTRODUCTION}

Longevity and the chronic profile of the health problems of a population may lead to a reduction in the functionality of the elderly and increase their degree of dependence in activities of daily living. Because of these situations, in many cases such individuals become dependent on care $^{1,2}$. Such individuals are responsible for providing care to dependent elderly persons, thus improving their quality of life ${ }^{3}$.

The profile of caregivers of the elderly has been identified in Brazilian and international literature as being informal, a family member, a woman (usually a wife or daughter), middle aged or elderly, married, with low levels of schooling and who lives with the elderly recipient of care ${ }^{4-9}$.

The task of caring can generate negative impacts on the health of the caregiver, such as overload or burden resulting from stress ${ }^{3,10}$. Other negative effects arising from the task of caring may also occur, the most common of which are depression, anxiety, physical, psychological and/or social exhaustion ${ }^{10}$.

Some conditions may be associated with the commitments of the care provided and have a negative influence on the biopsychosocial health of the caregiver. These include the hours dedicated to care, the lack of time for self-care, the duration of the illness and the increasing dependence of the elderly, as well as the reduction of work, social and leisure activities ${ }^{10}$.

The relationship between cognitive changes and the delivery of care has been discussed in literature ${ }^{11}$. A study carried out with elderly family caregivers of patients with dementia found that these caregivers can suffer cognitive and psychophysiological dysfunctions, which can affect their quality of life and the ability to provide care. The authors of this same study observed that levels of brain-derived neurotrophic factor (BDNF) were affected by the chronic stress of caregivers, and were partially related to cognitive deficits. They found that younger caregivers had significant cognitive dysfunctions, and that these were even more pronounced among older caregivers ${ }^{11}$.
The chronic stress found in the task of caring seems to be associated with cognitive decline ${ }^{11}$. According to Figueiredo et $\mathrm{al}^{12}$, instrumental activities of daily living (IADL) and advanced activities of daily living (AADL) are best performed by people with effective cognitive functioning. In this sense, caregivers need to have good cognitive performance to provide proper care, including, for example, in areas such as attention and concentration ${ }^{13}$.

One of the tools used to evaluate attention and concentration is Auditory Evoked Potential (P-300), which is highly dependent on cognitive abilities ${ }^{14}$. This potential is measured by the evaluation of latency and amplitude and is characterized by a wave resulting from the discrimination of a rare stimulus, which emerges approximately 300 milliseconds (ms) after the initial stimulus ${ }^{15}$. The peak latency of P300 can range from 270 to $470 \mathrm{~ms}$, depending on the proposed activity, although maximum amplitude occurs at about $300 \mathrm{~ms}^{14,16}$. A review by Pavarini et al. ${ }^{17}$ found that, for healthy elderly persons, amplitude values ranged from $2.2 \mu \mathrm{V}$ to $18.5 \mu \mathrm{V}$ and, for latency, from $320 \mathrm{~ms}$ to $484 \mathrm{~ms}$.

Adequate social support may represent a strategy for reducing the level of stress caused and, consequently, improving the health of the caregiver, resulting in improvements in the care provided ${ }^{4,18}$. In addition to providing better care, the mental health of caregivers can be improved if they receive sufficient social support ${ }^{18}$. Literature has shown that social relations benefit the cognitive functioning of the elderly ${ }^{19}$. It is therefore necessary to reinforce the importance of providing appropriate social support to the elderly, whether they are caregivers or not..

There is also a gap in literature exploring cognitive processing and social support among elderly caregivers. The objective of the present study was therefore to analyze measures of social support and cognitive processing in two groups of elderly persons, caregivers and non-caregivers.

\section{METHOD}

A comparative cross-sectional study was carried out based on the assumptions of quantitative research, involving elderly patients treated at the 
primary care service of a municipal region in the countryside of the state of São Paulo, in the southeastern region of Brazil.

The participants were divided into two groups: elderly caregivers of other elderly persons and noncaregiver elderly persons. To preserve anonymity, the acronyms $\mathrm{C}$ (elderly caregiver) and $\mathrm{N}$ (elderly non-caregiver), followed by a number, were used to identify each of the participants of the research. In order to place the elderly in their respective groups, some inclusion criteria were established:

- Group G1: 60 years of age or older, enrolled in the primary health care service of the municipal region and the primary caregiver of a dependent elderly resident in the same household. It should be noted that other non-elderly persons could live in the same household, such as children, grandchildren, and nephews and nieces, among others. Elderly patients who reported being dependent in at least one basic (BADL) or instrumental (IADL) activity of daily living, evaluated by the Katz Index ${ }^{20}$ and the Lawton and Brody ${ }^{21}$ scale, respectively, were considered dependent. These instruments were also applied to the elderly caregivers, who should be more independent than the elderly person with whom they lived.

- Group G2: 60 years of age or over, enrolled in the primary health care service of the municipal region, not provide any kind of care to another elderly person and reside alone or with another non-elderly family member. Participants with self-reported neurological disorders, a history of strokes and alcoholism and/or psychoactive drug use were excluded.

A sample calculation was performed using the mean comparison method between the two groups, setting the significance level at 5\% (alpha or type I error) and the power of the sample at $80 \%$ (beta or type II error at $20 \%$ ). The values of mean and standard deviation were estimated from a previous study performed with elderly caregivers and elderly persons enrolled in primary care units. A sample of 41 subjects per group was therefore determined ${ }^{22}$.

Data collection was performed from June 2016 to July 2017 and occurred in two stages. In the first stage, the interviewers, based on lists provided by the health services, visited the elderly in their homes and invited them to participate. After accepting and signing a Free and Informed Consent Form (FICF), information on sociodemographic characteristics, health and care was collected. A time for the second part of the interview, with a maximum gap of one week, was also established.

In the second stage, data on cognitive processing, cognition and social support were collected. This stage was carried out in a previously defined location in the neighborhood itself and which was easily accessible for the participants, ensuring a quiet, relaxed and well-lit environment.

The variables of interest were investigated using the following measures:

- Sociodemographic characteristics and health: gender (female or male), age (years), schooling (years), marital status (with or without a spouse).

- Characteristics of care: Caregiver (spouse, child), duration of care (years), hours per day dedicated to care, whether received material/financial help (yes or no), or emotional/emotional help (yes or no)

- Social support: assessed by Medical Outcomes Study (MOS), validated for the Brazilian population by Andrade et al. ${ }^{23}$, composed of 19 items referring to five dimensions of support: material, affective, emotional, positive social interaction and information. Scores vary from 15 to 100 points, with higher scores representing higher levels of social support received in that domain ${ }^{23}$.

- Cognition: evaluated by the Addenbrooke Cognitive Examination-Revised (ACE-R), validated for the Brazilian context by Carvalho and Caramelli24, composed of five domains - attention and orientation, memory, fluency, language and visuospatial. Total scores range from zero to 0-100, with higher scores representing better cognitive status ${ }^{24}$.

- Cognitive processing (P300): obtained by capturing the long-latency auditory evoked potentials using the Neuron-Spectrun-4/EPM model. The contact electrodes were fixed in the frontal $(\mathrm{Fz})$, central $(\mathrm{Cz})$, parietal $(\mathrm{Pz})$ regions, according to 
the 10/20 international system. Electrodes were also placed in the right (A1) and left (A2) earlobes and a reference electrode connected by cables (jumper - $\mathrm{A}+$ ) was used. The artifacts related to non-cerebral signals (blinking and muscular movements around the eyes) were removed, with the aid of the additional EOG channel (electrooculogram). The P300 was captured using the oddball paradigm, with a binaural stimulus sequence, containing two signals of the same intensity $(90 \mathrm{~dB})$. Within the sequence, the standard stimulus $(1000 \mathrm{~Hz})$ was triggered $80 \%$ of the time, while the rare stimulus $(2000 \mathrm{~Hz})$ was randomly interposed between the standard stimuli $20 \%$ of the time. For the P300 values the third positive wave that occurs $300-500 \mathrm{~ms}$ after the presentation of the rare stimulus was considered. From these findings two items of information were extracted: latency - considering the time elapsed between the rare stimulus and the P300 peak (in milliseconds) and amplitude - the peak P300 value (in microvolts) ${ }^{18}$. Lower latency and greater amplitude of the generated waves reflected better cognitive processing.

All the ethical aspects governing human research were respected. The study was authorized by the Health Department of the city of São Carlos and approved by the Research Ethics Committee of the Universidade Federal de São Carlos (CAAE: 51773915.1.0000.5504). Data collection began following approval.

All the data were double-entered into a spreadsheet and the data was validated and conferred. These results were subsequently transferred to the Statistical
Package for the Social Science (SPSS) version 20.0 program for statistical analyzes.

Following descriptive analysis, the ShapiroWilk test was used to verify the normality of the data. For comparison between groups, the MannWhitney test was used as the data was independent and non-parametric. A significance level of $p \leq 0.05$ was considered.

\section{RESULTS}

In $\mathrm{G} 1$, the majority of the elderly were female $(\mathrm{n}=33,80.5 \%)$, married $(\mathrm{n}=34,82.9 \%)$, had a mean age $68.5( \pm 5.8)$ years and a mean $4.5( \pm 3.7)$ years of schooling. Regarding the context of care, the elderly caregivers had provided care for $18.0( \pm 18.4)$ years on average and provided care for $6.5( \pm 5.1)$ hours per day. In $\mathrm{G} 2$, the majority were female $(\mathrm{n}=31,75.6 \%)$, widowed $(\mathrm{n}=23,56.1 \%)$, with a mean age of $69.8( \pm$ 7.2) years and a mean $3.7( \pm 2)$ years of schooling. The mean number of friends or close relatives was $4.6( \pm 2.7)$ for $\mathrm{G} 1$ and 4.8 ( \pm 3.7$)$ for G2. There was no statistical difference between the groups.

Table 1 presents data from the comparative analysis of social support for groups G1 and G2. There was no statistically significant difference between the groups, although the elderly persons in G2 had better scores in all areas of social support. The highest mean in both groups was for affective support (G1: 90.4, [ \pm 18.5$]$ / G2: 93.1, [ \pm 16.1$])$. The lowest G1 mean score was for positive social interaction support $(85.4 ;[ \pm 21.1])$. In $G 2$, the lowest means were for material $(90.7,[ \pm 18.9])$ and emotional support $(90.7,[ \pm 18.6])$.

Table 1. Comparative analysis of the social support of the elderly caregivers (G1) and the elderly non-caregivers (G2) groups, according to the scores obtained in the domains of Medical Outcomes Study (MOS). São Carlos, São Paulo, 2017.

\begin{tabular}{|c|c|c|c|c|c|}
\hline \multirow{2}{*}{ Variable } & \multicolumn{2}{|l|}{ G1 } & \multicolumn{2}{|l|}{ G2 } & \multirow{2}{*}{$p$-value } \\
\hline & Mean $\left( \pm\right.$ sd $\left.^{*}\right)$ & Min-max & Mean $( \pm$ sd $)$ & Min-max & \\
\hline Material support & $89.5( \pm 16.9)$ & $40-100$ & $90.7( \pm 18.9)$ & $25-100$ & 0.290 \\
\hline Affective support & $90.4( \pm 18.5)$ & $20-100$ & $93.1( \pm 16.1)$ & $20-100$ & 0.461 \\
\hline Emotional support & $88.5( \pm 19.3)$ & $20-100$ & $90.7( \pm 18.6)$ & $35-100$ & 0.482 \\
\hline Positive social interaction support & $85.4( \pm 21.1)$ & $10-100$ & $91.0( \pm 16.6)$ & $40-100$ & 0.321 \\
\hline Information support & $87.8( \pm 17.5)$ & $20-100$ & $91.6( \pm 14.8)$ & $50-100$ & 0.255 \\
\hline
\end{tabular}


It can be seen in Table 2 that the total ACE-R score was 65.3 ( \pm 16.3$)$ for $G 1$ and 65.8 ( \pm 15.2$)$ for G2. The mean scores obtained in the groups did not present significant differences. However, the highest mean occurred in the language domain, in both groups (G1: 19.7, [ \pm 4.7$]$ / G2: 18.8, [ \pm 4.6$])$.

Regarding cognitive processing, it can be seen in Table 3 that although there was no significant difference between the groups, G2 had the highest means in Pz Latency (355.4 [ \pm 39.3]), Fz Amplitude (5.5, [ \pm 4.4]), $\mathrm{Cz}$ Amplitude (5.4 [ \pm 4.8]) and $\mathrm{Pz}$ Amplitude (6.3 [ \pm 4.0$])$. Among the two groups, the highest latency value was in G1 (Fz Latency: 357.7, [ \pm 40.2]) and the lowest was in G2 (Fz Latency: 352.1, [ \pm 39.8] ). In terms of amplitude, the highest value was found in G2 (6.3, [ \pm 4.0]) for Pz Amplitude, and the lowest was in G1 (4.7, [ \pm 4.0]) for Cz Amplitude.

Table 2. Comparative analysis of the cognition of the groups of elderly caregivers (G1) and non-caregivers (G2), according to the scores obtained in the Addenbrooke's Cognitive Examination-Revised (ACE-R) domains. São Carlos, São Paulo 2017.

\begin{tabular}{|c|c|c|c|c|c|}
\hline \multirow{2}{*}{ Cognition } & \multicolumn{2}{|l|}{ G1 } & \multicolumn{2}{|l|}{ G2 } & \multirow{2}{*}{$p$-valu } \\
\hline & Mean $\left( \pm\right.$ sd $\left.^{*}\right)$ & Min-max & Mean $( \pm s d)$ & Min-max & \\
\hline ACER - Total & $65.3( \pm 16.3)$ & $35-92$ & $65.8( \pm 15.2)$ & $37-93$ & 0.878 \\
\hline Attention/Orientation & $13.7( \pm 2.3)$ & $8-18$ & $14.0( \pm 2.4)$ & $8-18$ & 0.398 \\
\hline Memory & $14.8( \pm 5.9)$ & $4-25$ & $15.8( \pm 5.6)$ & $6-26$ & 0.463 \\
\hline Fluency & $6.4( \pm 2.8)$ & $1-12$ & $6.4( \pm 2.7)$ & $1-11$ & 0.974 \\
\hline Language & $19.7( \pm 4.7)$ & $10-26$ & $18.8( \pm 4.6)$ & $9-26$ & 0.350 \\
\hline Visuospatial & $10.6( \pm 3.1)$ & $4-16$ & $10.7( \pm 3.0)$ & $5-16$ & 0.915 \\
\hline
\end{tabular}

*Standard deviation.

Table 3. Comparative analysis of the cognitive processing of the group of elderly caregivers of elderly persons (n=41) (G1) and non-caregivers (n=41) (G2). São Carlos, São Paulo, 2017.

\begin{tabular}{llllll}
\hline \multirow{2}{*}{ P300 } & G1 & & G2 & Min-max & $p$-value \\
\cline { 2 - 5 } & Mean $\left( \pm\right.$ sd $\left.^{*}\right)$ & Min-max & Mean $( \pm$ sd $)$ & $292-484$ & 0.512 \\
\hline Latency Fz & $357.7( \pm 40.2)$ & $288-496$ & $352.1( \pm 39.8)$ & $292-488$ & 0.521 \\
\hline Latency Cz & $353.2( \pm 37.2)$ & $280-430$ & $353.5( \pm 45.8)$ & $292-470$ & 0.827 \\
\hline Latency Pz & $353.4( \pm 36.4)$ & $280-430$ & $355.4( \pm 39.3)$ & $(-1.3)-16$ & 0.617 \\
\hline Amplitude $\mathrm{Fz}$ & $4.9( \pm 3.8)$ & $(-1.7)-15$ & $5.5( \pm 4.4)$ & $(-1.5)-21$ & 0.651 \\
\hline Amplitude $\mathrm{Cz}$ & $4.7( \pm 4.0)$ & $(-3.4)-18$ & $5.4( \pm 4.8)$ & $(-1)-19$ & 0.479 \\
\hline Amplitude $\mathrm{Pz}$ & $5.8( \pm 3.8)$ & $(-2.9)-18$ & $6.3( \pm 4.0)$ & & \\
\hline
\end{tabular}

*Standard deviation.

\section{DISCUSSION}

The results of the present study indicate a predominance of women, who were married and had low levels of schooling in G1. Corroborating the data from the present study, Anjos et al. ${ }^{5}$ observed that the majority of the participating caregivers were female, married, with low levels of schooling and who lived with the elderly. Other studies ${ }^{5,6,7,9,25}$ have also indicated the same caregiver profile.
Fuhrmann et al. ${ }^{26}$, in the city of Porto Alegre, Rio Grande do Sul, carried out a study with 112 elderly/caregivers linked to a basic care unit, with the objective of characterizing the elderly dependents and their main family caregivers and verifying the association between functional capacity and caregiver burden. The results of this study showed that the caregivers had a high level of education, with an average of $12.2( \pm 5.24)$ years of study, which differs from the data found here, 
where caregivers had an average of 4.5 years of schooling ( \pm 3.7$)$.

The mean age of the caregivers in this study was 68.5 ( \pm 5.8 ) years. A study of 338 elderly caregivers found that $39.3 \%$ of the participants were aged between 65 and 69 years, and $65.7 \%$ of these caregivers were female, corroborating the findings of the present study ${ }^{1}$. Further corroborating the data, a survey conducted in Bahia found that $34.5 \%$ of the caregivers were older than 61 years and $89.7 \%$ were female ${ }^{4}$. It is noteworthy that, as caregivers age, they may also acquire disabilities and experience greater difficulty when taking care of themselves and others, which may increase the vulnerability of both the caregiver and the elderly person receiving care ${ }^{9,13}$.

Regarding the care context, the elderly caregivers provided, on average, $18.0( \pm 18.4)$ years of care. A study carried out in the municipal region of Manoel Vitorino, in the state of Bahia, found that $68.8 \%$ of caregivers spent between two and ten years of their lives providing care and $20.8 \%$ provided care for over ten years ${ }^{5}$.

Regarding the time dedicated to care each day, the present study observed that caregivers spent 6.5 $( \pm 5.1)$ hours caring per day. This result differs from some Brazilian studies where, in 2014, $86.2 \%$ of the caregivers investigated by Anjos et al. ${ }^{4}$ devoted 18 to 24 hours to daily care, giving an average of 21.4 hours per day. Also, in 2015, Anjos et al. ${ }^{5}$ found that $88 \%$ of caregivers provided help to those in need for a period of 13-24 hours, averaging 21.9 hours per day $( \pm 4.9)$. The results may be related to differences in the degree of dependency of the elderly care recipients, since caring for a highly dependent elderly person, who requires more onerous care tasks, can generate greater burden on the caregiver, as it is a long-term task with a high daily care load ${ }^{5,10}$

There was a predominance of women and low levels of schooling in G2. Dias et al. ${ }^{27}$ observed that $63.1 \%$ of the elderly persons who participated in the study were female and $39.8 \%$ had low levels of schooling ( $0-3$ years of schooling), corroborating this and other studies ${ }^{6,7}$. It may be that the reason for the low levels of schooling in this study is the fact that most of the elderly are from highly socially vulnerable neighborhoods, according to the Paulista Social Vulnerability Index (IPVS).
In terms of marital status, the majority of G2 were widowed (56.1\%). Corroborating these findings, the Center for Study and Research in Physical Education (NEPEF/FACVEST) found, in one of its surveys, that most of the elderly participants $(n=35 ; 70 \%)$ were also widowed ${ }^{28}$. Being a widower can mean living alone. Literature has shown that living alone can mean more independence and autonomy. However, the family environment is a fundamental element in the well-being of the elderly, and family relationships are extremely important when dealing with solitude and other situations that may affect the life of an elderly person ${ }^{29}$.

In 2017, Lima-Costa et al. ${ }^{30}$ found an average age of 69.9 years among non-caregivers living in the community, the majority of whom were female (56.4\%). These data corroborate those found here. In another study, the authors found that $65.71 \%$ of the elderly participants were female, with one to four years of schooling $(49.23 \%)$ and a mean age of $72.32( \pm 5.55)$ years?

Regarding social support, there was no statistically significant difference between the groups, although the elderly in G2 had better scores in all areas of this form of support. In 2015, Anjos et al. ${ }^{5}$, using the score in the Social Relations domain of the Whoqol-bref instrument, which covers issues related to personal relations and social support and assistance, found that $41.4 \%$ of caregivers said they were satisfied in terms of such support. It is noteworthy that caregivers related the social support they received to direct care for the elderly. However, they stated that they did not receive formal social support.

Social support has an influence on the quality of life of the caregiver, as it allows greater freedom in activities of daily living, and may also prevent burden, biopsychosocial harm and complications to health ${ }^{5}$. Also regarding social support for caregivers, some studies have verified that, if suitable, such support can impact on the reduction of stress levels that result from the task of caring, improving the health of the caregiver and the care provided ${ }^{4,18}$.

An integrative review of literature carried out by Pereira ${ }^{31}$ found that social support was related to the well-being of the elderly. It was also observed that elderly persons can receive different types of social support, such as from family, community, 
friends, groups for the elderly, self-help groups, and formal support (cited in 50\% of articles, where only specialist doctors and those accompanying the treatment were mentioned).

It is also emphasized that in circumstances where social support is low and the social support network is weak or non-existent, the risks of increased vulnerability and disease are aggravated ${ }^{32}$. Social and emotional support networks should be seen as tools for coping with life events caused by stressful situations and the disorders associated with them. As the years go by, the significance of the social network and social support increases. ${ }^{32}$.

A nationwide study of elderly participants with functional limitations aimed to describe the prevalence and sociodemographic factors associated with the informal and paid help that these elderly people received. It was observed that the most frequently reported aid was informal $(81.8 \%)$, followed by paid $(5.8 \%)$ or mixed $(6.8 \%)$, and, lastly, none $(5.7 \%)$. The same study found that the greater the number of residents in the household, the greater the propensity to receive help, regardless of source, age and gender. Also, as age increased, people who lived alone were more likely to receive help. The participants who received informal, paid or mixed assistance were more likely to be women and live at home with others and with older people, in comparison with those who did not receive any kind of help $(75 \text { or more years of age })^{30}$.

The total mean ACE-R score in G1 was 65.3 $( \pm 16.3)$ points. A cross-sectional study carried out in a city in the state of São Paulo with 343 elderly caregivers enrolled in Family Health Units in urban, rural and high vulnerability contexts, found that $54.5 \%$ of the 189 urban elderly scored above the cut-off point ( 65 points) on the ACE-R instrument, corroborating the results found in this study. The same study also found that, in the rural context, $58.0 \%$ of 81 elderly caregivers achieved scores above the aforementioned cut-off point adopted by the study. Of elderly caregivers in a high vulnerability context, $19.2 \%$ of the 73 participants scored above the cut-off grade. In 2017, Brigola et al. ${ }^{26}$, in a study with elderly caregivers living in rural communities, found a mean ACE-R score of 68.7 ( \pm 15.5), which also agreed with the findings of the present study.
The mean score of the ACE-R instrument in G2 was $65.8( \pm 15.2)$ points. Nunes et al. ${ }^{33}$ observed that $76.9 \%$ of the elderly participants in a study experienced cognitive decline, among whom there was a higher percentage of women and a greater proportion of dependent elderly people. Among those with cognitive decline, there was a greater prevalence of those who were $\geq 80$ years old, widowers, who lived with children and had low levels of schooling (1-3 years of study). In a municipal region in the northern state of Rio Grande do Sul, Stamm et al. ${ }^{29}$ found that of 368 elderly participants, 204 (55.4\%) had cognitive deficits.

A study by Casemiro et al. ${ }^{34}$ revealed a mean total score of $89.3( \pm 4.0)$ points, which differed from the results of the present study. A probable explanation for this discrepancy may be the difference in schooling among the participants of these studies, as the participants of the study by Casemiro et al. ${ }^{34}$ had high levels of schooling. Low schooling, among other factors, is associated with a higher prevalence of cognitive decline ${ }^{33}$.

Regarding cognitive processing, there was no significant difference between the groups. However, G2 had higher means in Pz Latency, Fz Amplitude, $\mathrm{Cz}$ Amplitude and $\mathrm{Pz}$ Amplitude. A systematic review by Pavarini et al. ${ }^{17}$ identified 26 studies that together involved 940 healthy elderly individuals, most of which sought to identify and determine how P300 is influenced by age. The results showed that $\mathrm{P} 300$ amplitude values ranged from $2.2 \mu \mathrm{V}$ to $18.5 \mu \mathrm{V}$, while in the present study the variation in $\mathrm{G} 1$ was $(-1.7)$ to $15,(-3.4)$ to 18 and (-2.9) to 18, for Fz Amplitude, $\mathrm{Cz}$ Amplitude and $\mathrm{Pz}$ Amplitude, respectively, and the variation in G2 was (-1.3) to $16,(-1.5)$ to 21 and (-1) to 19 for the same amplitudes. In terms of latency, the systematic review found values ranging from 320 $\mathrm{ms}$ to $484 \mathrm{~ms}$. In the present study, the $\mathrm{Fz}, \mathrm{Cz}$ and $\mathrm{Pz}$ Latency values in G1 ranged from 288 to 496, 280 to 430 and 280 to 430 , respectively, while in G2 they varied from 292 to 484, 292 to 488 and 292 to 470 for same latencies. The authors affirm that these variations in the amplitudes and latencies analyzed may be related to the methodologies adopted, the variables studied and the samples observed in these studies. It is important to point out that the characteristics of the sample and the 
way the test is applied also influence the values of amplitude and latency ${ }^{35}$.

Some limitations of the present study should be highlighted, notably that it is a cross-sectional study carried out with a specific sample and the data can therefore not be generalized, nor is it possible to establish a cause and effect relationship. In addition, the groups were similar, but not matched. However, the results of this study can serve as a basis for future research, which can be performed with a larger number of participants, the insertion of other groups from different contexts and regions, or through the longitudinal follow-up of these elderly people.

\section{CONCLUSION}

The results showed that there were no significant differences between groups in terms of social support, cognition and cognitive processing.

\section{REFERENCES}

1. Tomomitsu MRSV, Perracini MR, Neri AL. Fatores associados à satisfação com a vida em idosos cuidadores e não cuidadores. Ciênc Saúde Colet. 2014;19(8):3429-40.

2. Lima PV, Valença TDC, Chaves RN, Reis LA. Memória de idosos longevos com dependência funcional a respeito do trabalho. Rev Ciênc Desenvol. 2016;9(1):172-90.

3. Bandeira M, Tostes JGA, Santos DCS, Lima DC, Oliveira MS. Sobrecarga de familiares cuidadores de pacientes psiquiátricos: relação com assertividade. Psico USF. 2014;19(3):399-409.

4. Anjos KF, Boery RNSO, Pereira R, Santos VC, Boery EN, Casotti CA. Perfil de cuidadores familiares de idosos no domicílio. Rev Pesqui Cuid Fundam (Online). 2014;6(2):450-61.

5. Anjos KF, Boery RNSO, Pereira R, Pedreira LC, Vilela ABA, Santos VC, et al. Associação entre apoio social e qualidade de vida de cuidadores familiares de idosos dependentes. Ciênc Saúde Colet [Internet]. 2015 [acesso em 01 set. 2018];20(5):1321-30.

Disponível em: http://www.scielo.br/pdf/csc/v20n5/ pt_1413-8123-csc-20-05-01321.pdf
The majority of the elderly in Group 1 were women, married, had a mean age of 68.5 years and had, on average, 4.5 years of schooling. The elderly caregivers provided care, on average, for 18.0 years, with 6.5 hours of daily care. In Group 2, the majority were women, widowed, with a mean age of 69.8 years and a mean of 3.7 years of schooling.

In the present study, being a caregiver did not mean having less social support, worse cognition or cognitive processing. This may mean that caring for the elderly does not necessarily negatively interfere with cognition and cognitive processing, or in other words, the elderly caregiver does not necessarily have worse memory, verbal fluency, visuospatial skills, attention, or concentration. Considering the characteristics of this sample, from the context in which they live and based on the methods of the study, being an elderly caregiver does not mean having fewer people to rely on.

6. Andrade NB, Novelli MMPC. Perfil cognitivo e funcional de idosos frequentadores dos centros de convivência para idosos da cidade de Santos, SP. Cad Bras Ter Ocup. 2015;23(1):143-52.

7. Sposito G, Neri AL, Yassuda MS. Atividades avançadas de vida diária (AAVDs) e o desempenho cognitivo em idosos residentes na comunidade: Dados do Estudo FIBRA Polo UNICAMP. Rev Bras Geriatr Gerontol. 2016;19(1):7-20.

8. Pinquart M, Sorensen S. Spouses, adult children, and children-in-law as caregivers of older adults: a metaanalytic comparison. Psychol Aging. 2011;26(1):1-14.

9. Pavarini SCI, Neri AL, Brigola AG, Ottaviani AC, Souza EN, Rossetti ES, et al. Idosos cuidadores que moram em contextos urbanos, rurais e de alta vulnerabilidade social. Rev Esc Enferm USP [Internet]. 2017 [acesso em 01 set. 2018];51:1-7. Disponível em: http://www.scielo.br/pdf/reeusp/v51/ pt_1980-220X-reeusp-51-e03254.pdf

10. Souza LR, Hanus JS, Libera LBD, Silva VM, Mangilli EM, Simões PW, et al. Sobrecarga no cuidado, estresse e impacto na qualidade de vida de cuidadores domiciliares assistidos na atenção básica. Cad Saúde Colet [Internet]. 2015 [acesso em 03 set. 2018];23(2):140-49. Disponível em: http://www.scielo. br/pdf/cadsc/v23n2/1414-462X-cadsc-23-2-140.pdf 
11. Corrêa MS, Giacobbo BL, Vedovelli K, Lima DB, Ferrari P, Argimon IIL, et al. Age effects on cognitive and physiological parameters in familial caregivers of Alzheimer's Disease patients. PloS ONE [Internet]. 2016 [acesso em 03 set. 2018];11(10):1-16. Disponível em: http://journals.plos.org/plosone/ article? $i d=10.1371 /$ journal.pone.0162619

12. Figueiredo CS, Assis MG, Silva SLA, Dias RC, Mancini MC. Functional and cognitive changes in community-dwelling elderly: longitudinal study. Braz J Phys Ther. 2013;17(3):297-306.

13. Brigola AG. Perfil cognitivo, fragilidade, sintomas depressivos e sobrecarga de idosos cuidadores em comunidades rurais [dissertação]. São Carlos: Universidade Federal de São Carlos; 2016.

14. Cóser MJS, Cóser PL, Pedroso FS, Rigon R, Cioqueta E. P300 Auditory evoked potential latency in elderly. Braz J Otorhinolaryngol. 2010;76(3):287-93.

15. Rossini PM, Rossi S, Babiloni C, Polich J. Clinical neurophysiology of aging brain: from normal aging to neurodegeneration. Prog Neurobiol. 2007;83(6):375-400.

16. Dinteren RV, Arns M, Jongsma MLA, Kessels RPC. P300 Development across the Lifespan: a systematic review and meta-analysis. PloS ONE. 2014;9(2):873-47.

17. Pavarini SCI, Brigola AG, Luchesi BM, Souza EN, Rossetti ES, Fraga FJ, et al. On the use of the P300 as a tool for cognitive processing assessment in healthy aging: a review. Dement Neuropsychol [Internet]. 2018 [acesso em 03 set. 2018];12(1):1-11. Disponível: http://www.scielo.br/pdf/dn/v12n1/1980-5764dn-12-01-0001.pdf

18. Guedes MBOG, Lima KC, Caldas CP, Veras RP. Apoio social e o cuidado integral à saúde do idoso. Rev Saúde Colet. 2017;27(4):1185-1204.

19. Kelly ME, Duff H, Kelly S, Power JEM, Brennan S, Lawlor BA, et al. The impact of social activities, social networks, social support and social relationships on the cognitive functioning of healthy older adults: a systematic review. Syst Rev J [Internet]. 2017 [acesso em 03 set 2018];6(259):5-18. Disponível: https:// systematicreviewsjournal.biomedcentral.com/ articles/10.1186/s13643-017-0632-2\#comments

20. Lino VTS, Pereira SRM, Camacho LAB, Ribeiro Filho ST, Buksman S. Adaptação transcultural da escala de independência em atividades da vida diária (Escala Katz). Cad Saúde Pública. 2008;24(1):103-12.

21. Santos RL, Virtuoso JSJ. Confiabilidade da versão brasileira da escala de atividades instrumentais da vida diária. Rev Bras Promoç Saúde. 2008;21(4): 290-6.
22. Hulley SB, Cummings SR, Browner WS, Grady DG, Newman TB. Delineando a pesquisa clínica. 4 ed. Porto Alegre: ArtMed; 2015.

23. Andrade CR, Chor D, Faerstein E, Rosane RH, Lopes CS, Fonseca MJM. Apoio social e auto-exame das mamas no Estudo PróSaúde. Cad Saúde Pública. 2005;21(2):379-86.

24. Carvalho VA, Caramelli P. Brazilian adaptation of the Addenbrooke's cognitive examination-revised (ACE-R). Dement Neuropsychol. 2007;1(2):212-6.

25. Brigola AG, Luchesi BM, Alexandre TDS, Inouye K, Mioshi E, Pavarini SCI. High burden and frailty: association with poor cognitive performance in older caregivers living in rural areas. Trend Psychiatry Psych. 2017;39(4):257-63.

26. Fuhrmann AC, Bierhals CCBK, Santos NOS, Paskulin LMG. Associação entre a capacidade funcional de idosos dependentes e a sobrecarga do cuidador familiar. Rev Gaúch Enferm. 2015;36(1):14-20.

27. Dias ED, Andrade FB, Duarte YAO, Santos JL, Santos JLF, Lebrão ML. Atividades avançadas de vida diária e incidência de declínio cognitivo em idosos: Estudo SABE. Cad Saúde Pública. 2015;31(8):1623-35.

28. Liposcki DB, Andreis LM, Silva SA, Neto FR. Aptidão motora de idosos longevos: implicações cognitivas e socioemocionais. Rev Kairós. 2016;19(22):227-39.

29. Stamm B, Leite MT, Hildebrandt LM, Kirchner RM, Girardon-Perlini NMO, Beuter M. Cognição e capacidade funcional de idosos que residem sós e com familiares. Rev Baiana Enferm. 2017;31(2):1-8.

30. Lima-Costa MF, Peixoto SV, Malta DC, Szwarcwald CL, Mambrini JVM. Cuidado informal e remunerado aos idosos no Brasil (Pesquisa Nacional de Saúde, 2013). Rev Saúde Pública. 2017;51(1):1-6.

31. Pereira JK. Evidências da influência da rede de apoio social na saúde de idosos brasileiros: revisão integrativa de leitura [monografia]. Brasília: Universidade de Brasília; 2015.

32. Maia CML, Castro FV, Fonseca AMG, Fernández IR. Redes de apoio social e de suporte social e envelhecimento ativo. Rev INFAD Psychol. 2016;1(1):293-304.

33. Nunes WA, Dias FA, Nascimento JS, Gomes NC, Tavares DMS. Cognição, funcionalidade e indicativo de depressão entre idosos. Rev Rene. 2016;17(1):103-11. 
34. Casemiro FG, Rodrigues IA, Dias JC, Alves LCS, Inouye K, Gratão ACM. Impacto da estimulação cognitiva sobre depressão, ansiedade, cognição e capacidade funcional em adultos e idosos de uma universidade aberta da terceira idade. Rev Bras Geriatr Gerontol. 2016;19(4):683-94.
35. Jiang S, Qu C, Wang F, Liu Y, Qiao Z, Qiu $\mathrm{X}$, et al. Using event-related potential P300 as an electrophysiological marker for differential diagnosis and to predict the progression of mild cognitive impairment: a meta-analysis. Neurol Sci. 2015;36(7):1105-12.

Received: June 06, 2018

Reviewed: September 17, 2018

Accepted: September 25, 2018 